\title{
Voltammetry Study of an Anti-HIV Compound by means of a Thin Organic Membrane
}

\author{
Achille Nassi, ${ }^{1,2}$ Thiery Christophe Ebelle, ${ }^{1,2}$ Joseph M. Dika Manga, ${ }^{2}$ \\ Jules-Blaise Mabou Leuna, ${ }^{1}$ Joel Donkeng Dazie, ${ }^{1}$ and Emmanuel Ngameni ${ }^{1}$ \\ ${ }^{1}$ Laboratoire de Chimie Analytique, Faculté des Sciences, Université de Yaoundé 1, BP 812, Yaoundé, Cameroon \\ ${ }^{2}$ Laboratoire de Chimie Minérale, Faculté des Sciences, Université de Douala, BP 24157, Douala, Cameroon \\ Correspondence should be addressed to Thiery Christophe Ebelle; thiercebel@yahoo.fr
}

Received 20 June 2013; Revised 17 August 2013; Accepted 20 August 2013

Academic Editor: Angela Molina

Copyright (C) 2013 Achille Nassi et al. This is an open access article distributed under the Creative Commons Attribution License, which permits unrestricted use, distribution, and reproduction in any medium, provided the original work is properly cited.

Cyclic and square wave voltammetries have been used to study electrochemical behaviour of an anti-HIV agent (Guttiferone A) at the liquid-liquid interface. The thin organic membrane is formed by an organic solvent containing redox probe. Guttiferone A, a benzophenone (BP) with appropriate electrolyte. It is demonstrated that BP possesses three reduction systems due to the redox transformation of the three tautomeric forms that lead to the migration of proton between the hydroxyl group in position 4 and the carbonyl group in positions 2 and 10. The transfer of proton from the aqueous solution to the organic phase is crucial for the redox transformation of BP into the organic membrane. The voltammograms obtained are strongly influenced by the $\mathrm{pH}$ of the aqueous phase. The electrochemical mechanism consists of $2 \mathrm{e}^{-} / 2 \mathrm{H}^{+}$exchange to form the separate redox compound $\mathrm{BPH}_{2}$.

\section{Introduction}

Numerous benzophenones reported in the literature are known to possess various biological activities [1]. Their antimicrobial activities are due to their ability to act as (i) potent inhibitors in electron transport [2], (ii) a model for the reduction of aromatic ketones, especially in an aqueous solution [3, 4 ] where the main product is benzopinacole, and (iii) mediator in the biosynthesis of a variety of polyisoprenylated benzophenones [5-8], a class of compounds which is not only chemically interesting due to their structurally complex features but also pharmacologically valuable.

More specifically, Guttiferone A (Figure 1) and its analogues are known to possess, antioxidant [9], cytotoxic [10, 11], and cancer chemopreventive [12] properties. Recent results revealed that Guttiferone A possesses different biological properties such as the cytoprotection against HIV-1 in vitro $[6,13]$. Most of the studies concerning Guttiferone are devoted to only biological aspects. The electrochemistry of Guttiferone is less described [14]. Electrochemistry is devoted to understanding the reactivity of molecules through the study of the changes in their properties during electron transfer processes. In many other research areas, such as pharmacology, these relationships are important, since they provide the basis for intelligent design of new drugs or treatments for specific diseases. The areas of research related to molecular, biochemical, and analytical electrochemistry for the analysis of reaction mechanisms and structure-reactivity relationships are of great importance in elucidating the human body's metabolic processing drugs and of the effect of drugs on the body [15-17].

In this work, our purpose is to describe redox properties of Guttiferone A using thinfilm electrodes in connection with voltammetric techniques. Modified electrodes are often constituted of a solid electrode covered with an organic phase which contains a compound having redox properties. Such electrodes are used, usually in contact with aqueous phases, for various reasons such as the study of the redox substance present in the organic medium when its insolubility in water does not allow a direct study in an aqueous environment. Thinfilm has same properties as an artificial organic-film membrane. Electrochemical techniques are very well suited for characterizing benzophenone-like compounds. As most of the physiologically active benzophenones are lipophilic, 


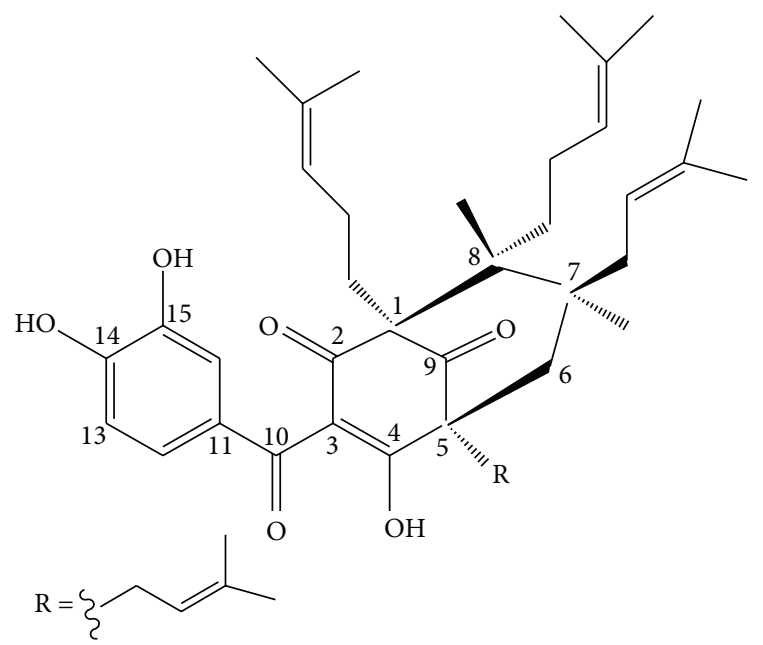

FIGURE 1: Molecular structure of Guttiferone A (BP).

electrochemical methods in nonaqueous medium have been developed. Particularly important are the biomimetic studies in which lipophilic benzophenones are embedded in a lipid membrane support on the electrode surface. Liposomes are also suitable for membrane immobilization of lipophilic benzophenone. In this context, we recently incorporated Lapachol to build an artificial light-driven transmembrane calcium pump and explain a new reduction mechanism of Lapachol in thinfilm electrode [15]. The aim of the work is to provide an insight in the redox chemistry of Gutifferone A, an important natural product embedded in an artificial membrane using the model developed by Shi and Anson $[18,19]$.

The device used by Shi is derived from the classical threeelectrode configuration depicted in Figure 2, the working electrode is covered with a thin film of organic solvent previously saturated with water in which the model compound and an appropriate electrolyte are dissolved. The electrode is then immersed in an aqueous electrolyte. The resulting device behaves like a stable liquid interface consisting of an organic membrane in contact with an aqueous phase.

The electrochemical experiments have been conducted with conventional cyclic (CV) and square wave voltammetry (SWV) techniques. The advantages of square wave voltammetry are a higher speed of analysis, a lower consumption of electroactive species, and reduction of problems related to the inhibition of the electrode surface. However, SWV is one of the most advanced voltammetry methods unifying the advantages of CV and pulse voltammetry techniques [20].

\section{Experimental}

2.1. Chemicals and Reagent. Guttiferone A (BP) was obtained from $\mathrm{CH}_{2} \mathrm{Cl}_{2}-\mathrm{MeOH}(1: 1)$ extract of Symphonia globulifera using a procedure described by Ngouela and coworkers [21]. The other chemicals were of high purity (99\%) and were obtained from Reidel de Häen and Merck. BP was dissolved in a water-saturated nitrobenzene (NB) mixture containing $0.1 \mathrm{M}$ tetrabuthylammonium perchlorate $\left(\mathrm{Bu}_{4} \mathrm{NClO}_{4}\right)$ as an organic electrolyte.

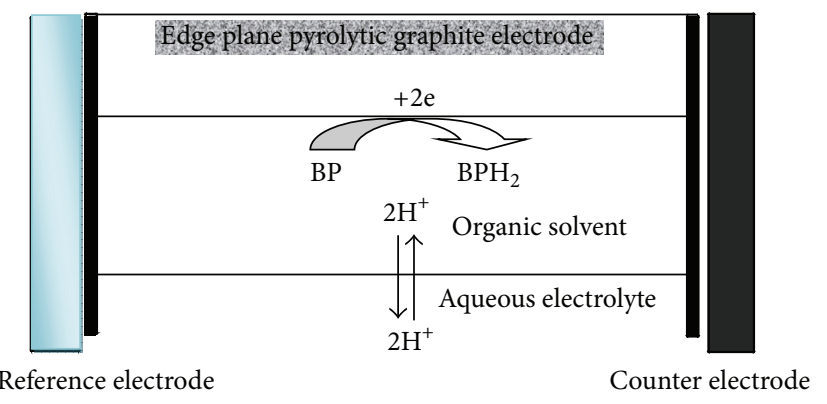

FIGURE 2: Plane edge pyrolytic graphite electrode covered with a micro film of electroinactive water immiscible organic solvent, containing a neutral redox probe and an organic electrolyte, immersed in an aqueous phase-buffered solution containing a common ion with the organic electrolyte. The modified electrode is used in a conventional three-electrode configuration.

2.2. Preparation of the Film. The modification and pretreatment of the working electrode were described elsewhere [15] as follow: the organic solution $(1 \mu \mathrm{L})$ was deposited on the graphite electrode with a micropipette; the organic solution spreads spontaneously over the electrode surface forming a stable film. The so-modified electrode was immersed in a phosphate buffer solution $\left(0.1 \mathrm{M} \mathrm{K}_{2} \mathrm{HPO}_{4}+0.1 \mathrm{M} \mathrm{KH}_{2} \mathrm{PO}_{4}\right)$. When necessary, $\mathrm{pH}$ values were adjusted by the addition of citric acid or hydroxide sodium. The aqueous phase is made of a $0.1 \mathrm{M} \mathrm{LiClO}_{4}$ solution. $\mathrm{NB}$-saturated water (purities select) was used throughout.

2.3. Electrochemical Cell and Measurements. As shown in Figure 2, a three-electrode system was used with a disk electrode $\left(0.32 \mathrm{~cm}^{2}\right)$ of edge plane highly oriented pyrolytic graphite as a working electrode. The reference electrode was a Saturated Calomel Electrode (SCE), and the counter electrode was a platinum wire. Prior to each experiment, solutions were deaerated thoroughly for at least $20 \mathrm{~min}$ with pure nitrogen. A positive pressure of this gas was maintained during subsequent work. Electrochemical data (cyclic voltammetry and SWV) were obtained using an Autolab Potentiostat (Eco-Chemie, Netherlands) driven by a PC with GPES electrochemical analysis software.

\section{Results and Discussion}

Before starting SWV measurements, the response of the organic film electrodes was thoroughly inspected by cyclic voltammetry in order to check the reproducibility and stability of the different forms of BP during successive potential cycling. Figure $3(\mathrm{~b})$ shows typical cyclic voltammogram obtained between 0.0 and $-1.9 \mathrm{~V}$ and corresponding to the electrolysis of the BP present in the organic film membrane in contact with an aqueous buffer solution at $\mathrm{pH}$ 1. During successive cycles, figure not shown, these CVs reflect the stability of the membrane and transformation of BP.

The CV consists of two distinct peaks (I-I' and II) which are not very sensitive to the potential scan rate. The peak pair $\mathrm{I} / \mathrm{I}^{\prime}$ is well developed and quasireversible, whereas the second, II, located at a more negative potential $(\Delta E=-1.3 \mathrm{~V})$, 


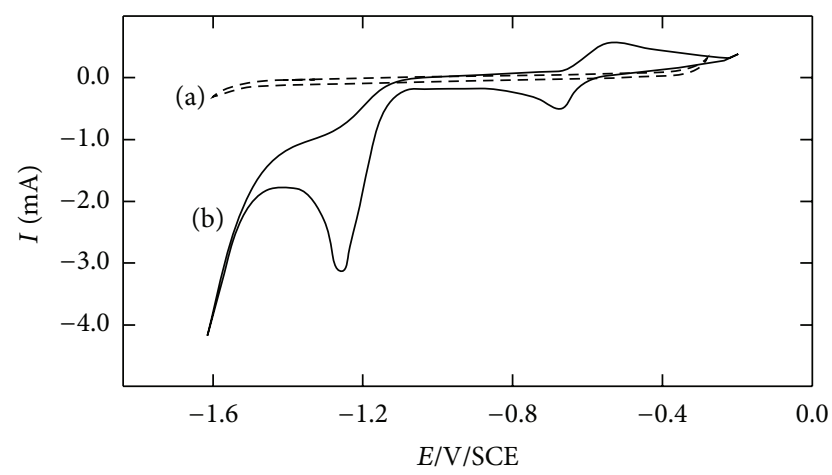

FIGURE 3: Cyclic voltammograms recorded with a: (a) thin filmelectrode without BP; (b) the thinfilm electrode containing $20 \mathrm{mM}$ of $\mathrm{BP}$ in contact with $0.1 \mathrm{M} \mathrm{LiClO}_{4}$ aqueous solution buffered with a $0.1 \mathrm{~mol} / \mathrm{L}$ phosphate buffer at $\mathrm{pH}=1$. Besides the redox probe, the organic phase contains $0.1 \mathrm{M}$ tetrabuthylammonium perchlorate $\left(\mathrm{Bu}_{4} \mathrm{NClO}_{4}\right)$ as an organic electrolyte. Scan rate was $v=20 \mathrm{mV} / \mathrm{s}$.

is irreversible. Both redox systems have previously been observed by classic cyclic voltammetry in aprotic medium or ionic liquid for other benzophenone [22-24]. The reduction of benzophenone in ionic liquid presents two reversible wellresolved one-electron reductions which were observed in dry liquid ionic which did not contain any readily available proton source. Upon addition of water or proton, the second process became chemically irreversible and shifted to a more positive potential by approximately $600 \mathrm{mV}$, moreover, the two reduction processes merged into a single two-electron proton-coupled process when a small among of proton is available in the media. This large dependence of potential on proton content which was not observed in molecular solvents, was explained by a reaction mechanism that incorporated protonation and hydrogen-bonding interaction of the benzophenone dianion with as many water molecules as possible [23].

It is well known that the scan rate can have a dramatic influence on peak separation. This is the case with couple I-I'. At low scan rate, $v=10 \mathrm{mVs}^{-1}$, the peak potential separations are $80 \mathrm{mV}$ and $90 \mathrm{mV}$ when the $\mathrm{pHs}$ of aqueous solution are 1 and 2, respectively; these values are not so far from the theoretical value of $60 \mathrm{mV}$ tabulated for a reversible one-electron process. An increase of the scan rate up to $v=30 \mathrm{mVs}^{-1}$ was accompanied by an increase of the separation of the couple

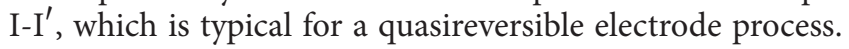
As a matter of fact, the transfer energy of the proton from the aqueous phase to the organic phase is too high $\left(32,5 \mathrm{~kJ} \cdot \mathrm{mol}^{-1}\right)$ [25], so that a slow scanning allows enough time to the protons to diffuse towards the surface of the electrode.

The evolution of CVs as functions of the scan rate when the $\mathrm{pH}$ is maintained constant is shown in Figure 4. In addition, the cathodic peaks I and II shifted towards more negative potentials with increasing scan rate. The inset of Figure 4 shows the variation of the scan rate-normalised cathodic peak current, $I_{p, c} / v$ versus $v$, for cathodic peak II. The ratio $I_{p} / v$ for cathodic peak decreases severely with an increasing scan rate, indicating a $\mathrm{CE}$ mechanism in which the electrode reaction is

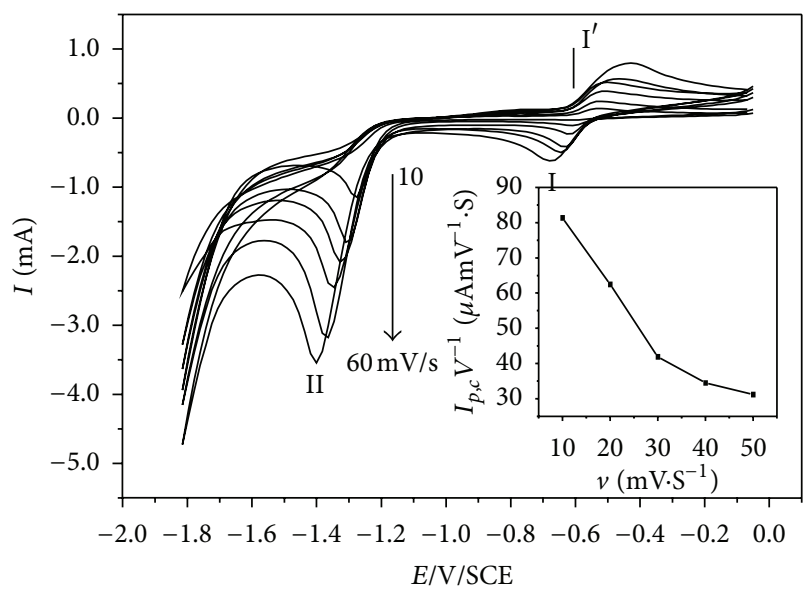

FIGURE 4: Effect of the scan rate on the cyclic voltammograms recorded with a thinfilm electrode in contact with an aqueous medium at $\mathrm{pH}=1$. The scan rate was $v=10$ to $60 \mathrm{mV} \cdot \mathrm{s}^{-1}$. The inset shows the variation of the ratio $I_{p, c} / v$ on the scan rate for the peaks II.

gated by a slow preceding chemical step $[15,26]$. These results suggest that the two systems are not similar. At this level, we cannot establish the fact that the system I/I' exchanges one electron. In order to shed more light on these systems and gather more information (e.g., the number of the electrons exchanged), some few experiments were done using square wave voltammetry, a more sensitive method especially when one deals with membrane processes [26-30]. The SWV technique is one of the most advanced voltammetric methods unifying the advantages of CV and pulse voltammetric techniques. In the course of a SW voltammetric experiment, the potential is repeatedly changed to an oxidative and reductive mode in a form of square-shaped potential pulses [31, 32]. Figure 5(a) compares typical $\mathrm{CV}$ and SWV recorded in an NB membrane in contact with an aqueous solution of $\mathrm{pH} 1$. Unlike the CV, SWV reveals a third system noted as III. The SWV response of BP in the NB in contact with an aqueous solution at $\mathrm{pH} 1$ consists of three well-defined and separated reductive peaks (Figure 5(b)). The three reductive peaks are well developed and separated. The processes I/I' and III/III' are clearly quasireversible, while the peak II reflects a totally irreversible electrochemical process in both electrochemical methods as indicated in Figure 5. The relative heights vary proportionally to the number of repetitive scans. It can be observed that in the course of these repetitive scans, the magnitude of peak II decreases over time, whereas peaks I and III increase in the same proportion. Figure 6 shows that the intensities of both systems evolve in opposite directions. If the electrode was kept for a certain period in contact with the aqueous solution under open circuit conditions or at the initial potential value, the duration of contact seems to have no effect on the shape of voltammograms, as the position of the tautomerism equilibrium was predominantly fixed by the $\mathrm{pH}$ of the medium. Table 1 clearly shows that when the electrode is in contact with the aqueous phase, the intensities of peaks I and III increase with resting time. The decrease in the peak 


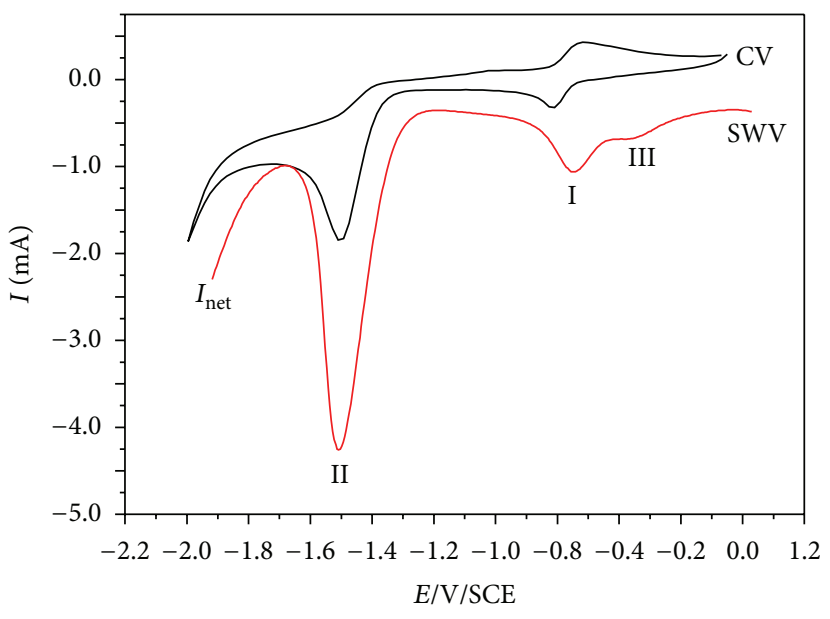

(a)

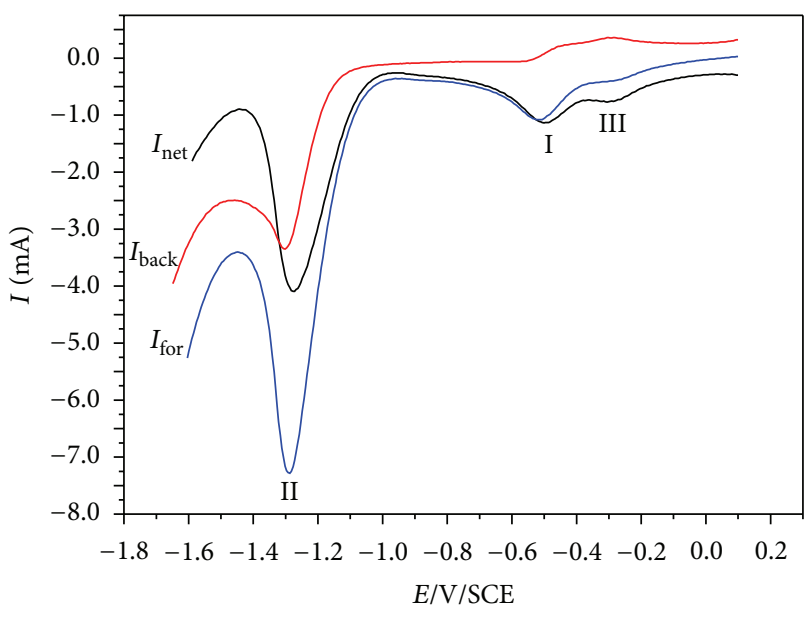

(b)

Figure 5: (a) Comparison of typical CV and SW voltammograms of $20 \mathrm{mM}$ of BP recorded in NB membrane in contact with an aqueous phase consisting of a buffer at $\mathrm{pH} 1$ and (b) Net SW voltammograms recorded with a the thinfilm electrode in contact with aqueous medium at $\mathrm{pH}=1$. For $\mathrm{CV}$, the sweep rate is $v=20 \mathrm{mV} \cdot \mathrm{s}^{-1}$, and for SWV the frequency is $f=12 \mathrm{~Hz}$, SW amplitude $E_{\mathrm{sw}}=50 \mathrm{mV}$ and step potential $\mathrm{dE}=1 \mathrm{mV}$.

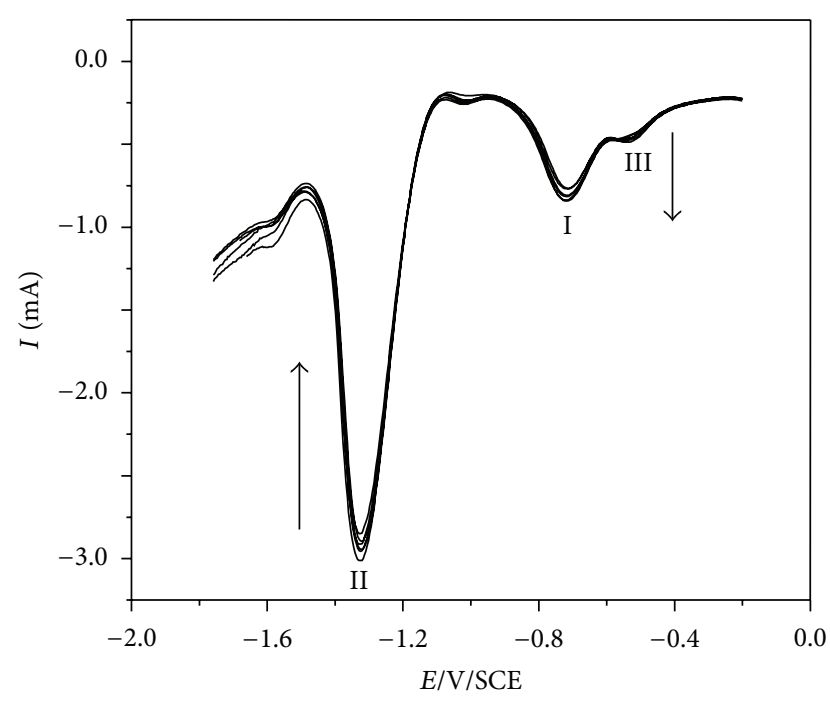

FIGURE 6: Consecutive net SWV voltammograms recorded with a thinfilm electrode in contact with aqueous medium at $\mathrm{pH}=1$. The other conditions are the same as for Figure 5.

current of system II reveals that the species that gave rise to this system is unstable. Contrary two this, the increase of intensities of systems I/I' and III/III' show that these species are stable and similar. This, indeed, tends to show that the concentration of molecular forms 1 and 3 (Scheme 1) increases in the membrane. By contrast, peak II decreases in the same time, showing that molecular form 2 is more stable in the membrane than molecular forms 1 and 3 . If the electrode was scanned starting at a potential located between the redox systems I and II (i.e., $E_{\text {rest }}=-1.20 \mathrm{~V}$ ), the magnitude of peak II remains unchanged no matter the duration of the contact between the electrode and the aqueous solution. In addition, it appears that the length of the electrode at this potential does not affect the signal of the peak II (Figure 7).
The behaviour of this system does not change with the restriction of the potential. Indicating that the electroactive species that generates the system II is not obtained after the processing of the process I. All these systems are affected by the repetition of the scan and the immersion time of the electrode in the aqueous phase. It, thus, appears that the electroactive species that gives rise to process II is not generated during the electrode process I (Figure 7). On the other hand, it is observed that the response of $\mathrm{BP}$ in the $\mathrm{NB}$ membrane is influenced by the $\mathrm{pH}$ of the aqueous phase. Figure 8 shows typical SWVs at different pHs. The relative heights and positions of the voltammetric peaks are strongly sensitive to the $\mathrm{pH}$. The evolution of the potential of each of the cathodic peaks I, II, and III as function of the $\mathrm{pH}$ varies linearly (data not shown) with a slope of about $60 \mathrm{mV} / \mathrm{pH}$, it is then clear that the redox processes I, II, and III involve an overall $2 \mathrm{e}^{-} / 2 \mathrm{H}^{+}$exchange, which is typical for $\mathrm{BP} / \mathrm{BPH}_{2}$ redox couple. The process II exhibits typical characteristics of a $\mathrm{CE}$ mechanism in which the electroactive reactant is supplied by a preceding chemical reaction. This is confirmed when the scan rate in CV and frequency SWV are varied for experimental arrangements. The overall voltammetric behavior of the studied compound strongly deviates from the common behavior of the $\mathrm{BP} / \mathrm{BPH}_{2}$ redox couple $[7,32]$. During the thinfilm experiment, the reduction of the BP must be accompagnied by an ion-transfer reaction across the organic solvent-water interface to maintain the charge's neutrality in the thin film. The proton transfer is a charge-compensating iontransfer reaction. The partition concentration of protons in the organic phase depends on $\Delta \phi_{\mathrm{W}}^{\mathrm{S}}$ as follows:

$$
\left[\mathrm{H}^{+}\right]_{\mathrm{S}}=\left[\mathrm{H}^{+}\right]_{\mathrm{W}} \exp \left[-\frac{F}{R T}\left(\Delta \phi_{\mathrm{W}}^{\mathrm{S}}-\Delta^{\mathrm{W} \rightarrow \mathrm{S}} \phi_{\mathrm{H}^{+}}^{\mathrm{S}}\right)\right]
$$

$\Delta \phi_{\mathrm{W}}^{\mathrm{S}}$ is the Galvani potential difference at the membranewater interface. We see that reduction the of BP under these conditions will be made at a less reductive potential. 


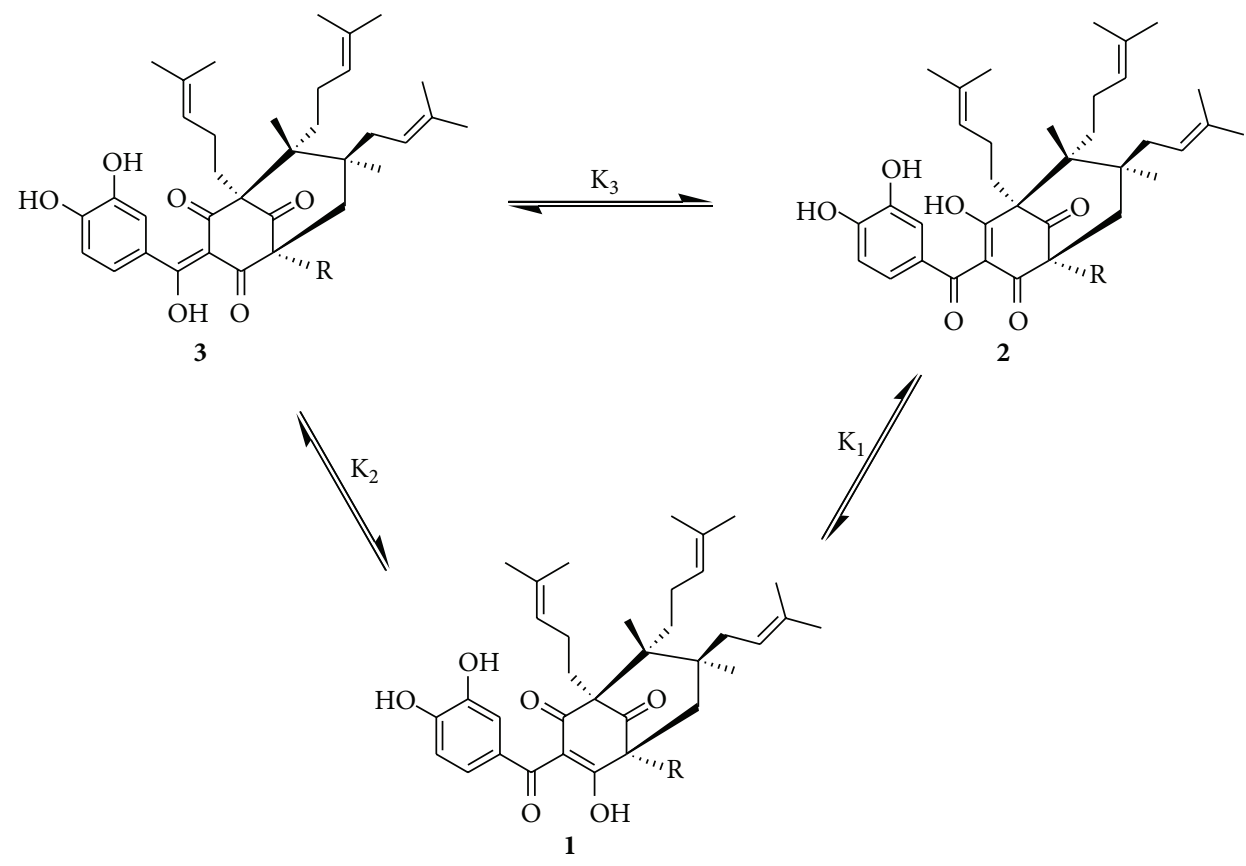

SCHEME 1

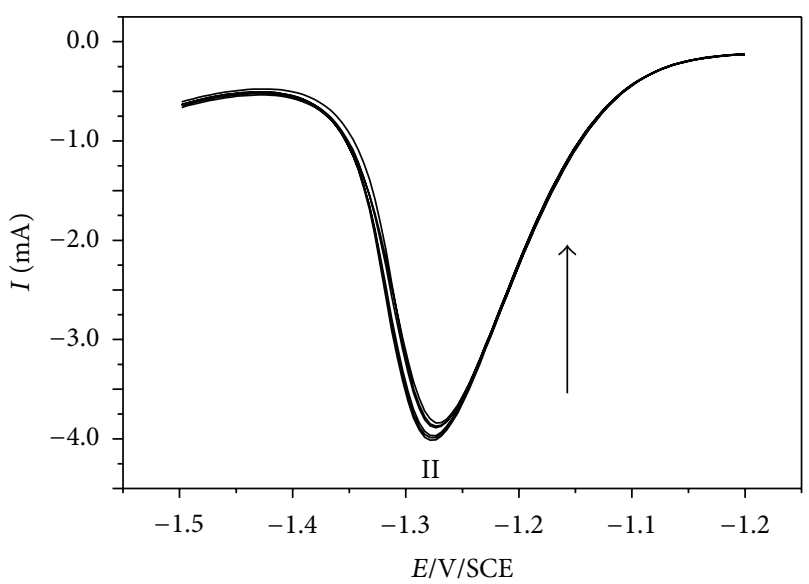

FIGURE 7: Effect of the resting potential on the net SW peak II, recorded with a thinfilm electrode in contact with an aqueous solution at $\mathrm{pH}=1$. The resting potential was $-0.3 \mathrm{~V}$. The time increases in the direction of the arrow from $0,25,50,75$ to $100 \mathrm{~s}$. The other conditions are the same as for Figure 5.

Moreover, the results presented in Figure 7 show that the electroactive reactant for the reductive process II is not generated in the previous electrochemical processes I and III. This excludes the possibility to explain the three reductive processes on the basis of three one-electron consecutive processes with a formation of stable radical-anion intermediate $\left(\mathrm{BP}^{\bullet-}\right)$. Furthermore, a careful inspection of the voltammetric curves in Figure 7 reveals that the current due to the second reductive process II slightly decreases with time. Therefore, the three electrochemical processes originate from redox transformations of three distinctive forms of BP molecule.
TABLE 1: Variation of intensity with the time of immersion of the electrode in aqueous phase at $\mathrm{pH} 1.5$, varied from 0 to $120 \mathrm{~s}$ with a step of $30 \mathrm{~s}$. Each voltammogram was recorded by imposing a new film on the electrode surface.

\begin{tabular}{lccc}
\hline & $I_{1}(\mu \mathrm{A})$ & $I_{2}(\mu \mathrm{A})$ & $I_{3}(\mu \mathrm{A})$ \\
\hline$t=0 \mathrm{~s}$ & 342 & 2440 & 41,4 \\
$t=30 \mathrm{~s}$ & 400 & 2430 & 61,7 \\
$t=60 \mathrm{~s}$ & 408 & 2420 & 65,8 \\
$t=90 \mathrm{~s}$ & 436 & 2350 & 68,0 \\
$t=120 \mathrm{~s}$ & 461 & 2280 & 68,6 \\
\hline
\end{tabular}

The interrelation of the peak magnitudes implies that the three redox forms are interconnected by equilibrium reaction. In addition, the stability of the systems I and III shows that they have a comparable nature. To check this assertion, by repetition of the scan, we recorded the curve of Figure 9 in the range potentials -0.2 and $-1.0 \mathrm{~V}$. The repetition of scan shows that the intensity of system III grows, while system I decreases. This suggests that the species which produce these processes are independent. The stability of process III results in the split of system I and confirms the presence of another tautomeric form of BP.

In the light of the preceding observation and considering the molecular structure of BP (Figure 1), it is reasonable to postulate that the intriguing voltammetric characteristic of the present compound originates from the influence of the hydroxyl and carbonyl groups. The carbonyl group in positions 2 and 10 can establish tautomerism equilibrium with the adjacent hydroxyl group in position 4 (Scheme 1). This was described by Martins et al. [33], who say that the tautomers of Gutifferone in general exist in a solution in a condition of equilibrium. 

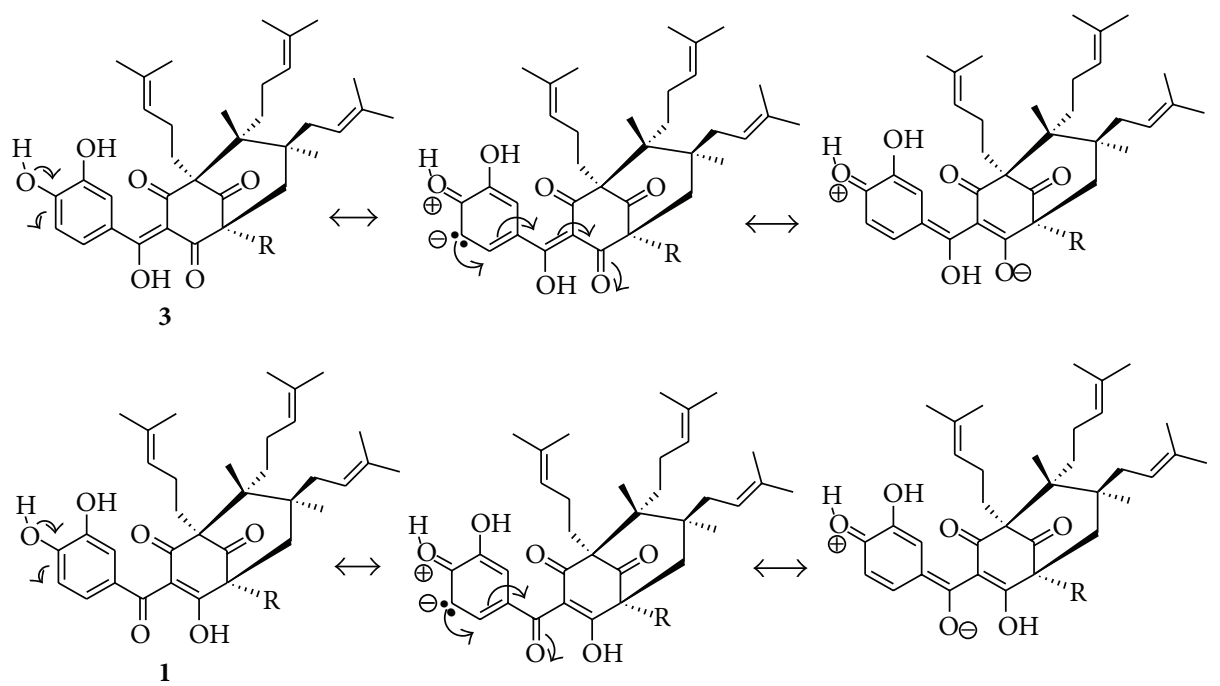

SCHEME 2

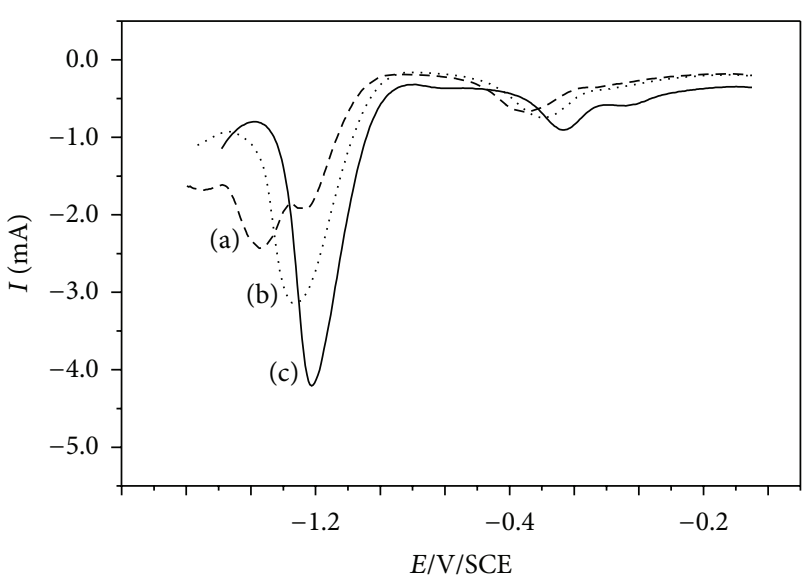

FIgURE 8: Square Wave Voltammetry at thinfilm electrode recorded in contact with aqueous medium at $\mathrm{pH}=0.46$ (a), 0.76 (b) and 1.00 (c). The parameters of the potential modulation are the same as for Figure 5.

The position of the tautomerism equilibrium $\mathrm{K}_{1}$ depends critically on the $\mathrm{pH}$ of the medium. This equilibrium is shifted toward the form 2 when the $\mathrm{pH}$ decreases, which is in agreement with the known acidic catalysis of the ketonol transformation. The slow establishment of the tautomer equilibrium explains the evolution of the square wave voltammograms under the repetitive cycling of the SWV potential modulation (Figure 6). Mesomerrism and intramolecular hydrogen-bonding can explain the stability of different tautomeric forms (Scheme 2). It is well known that intramolecular hydrogen-bonding causes the shift of the reduction peak potential towards less negative values $[23,34]$. Then, the reduction of the compounds $\mathbf{1}$ and $\mathbf{3}$ yields the same reduction product.

We see from Scheme 2 that the mesomeric form 3 is longer than mesomeric form 1 . It is well know that the molecule is more stable when its mesomeric is too long. This confirms the different tautomeric forms obtained.

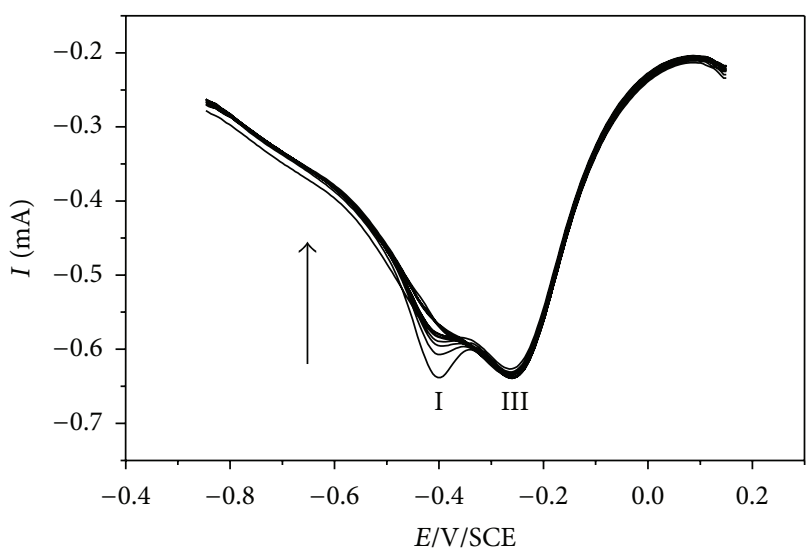

FIGURE 9: Consecutive net SWV voltammograms recorded with a thinfilm electrode in contact with aqueous medium at $\mathrm{pH}=1$. The parameters of the potential modulation are the same as for Figure 5.

The three tautomeric forms can undergo independent redox transformations to yield a hydroxyl form according to Scheme 3.

Reaction $\left(\mathrm{K}_{4}\right)$ is the common redox transformation of the keton/alcohol redox couple involving an overall $2 \mathrm{e}^{-} / 2 \mathrm{H}^{+}$ exchange, assigned to the reduction process I. The chemical equilibriums $\mathrm{K}_{2}$ and $\mathrm{K}_{1}$, coupled to the redox reactions $\mathrm{K}_{5}$ and $\mathrm{K}_{6}$, complete the $\mathrm{CE}$ mechanism scheme, thus being attributed to the reduction processes II and III. For the thinfilm experiment, the situation is particularly complex as the $2 \mathrm{e}^{-} / 2 \mathrm{H}^{+}$redox transformation in the membrane must be accompanied by a corresponding ion-transfer reaction across the membrane/water interface to maintain the charge neutrality of the membrane. If the proton transfer is the charge compensating ion-transfer reaction, the reaction $\mathrm{K}_{4}$ should be written as follows:

$$
\mathrm{BP}_{(\mathrm{NB})}+2 \mathrm{H}_{(\mathrm{W})}^{+}+2 \mathrm{e}^{-} \rightleftarrows \mathrm{BPH}_{2(\mathrm{NB})}
$$



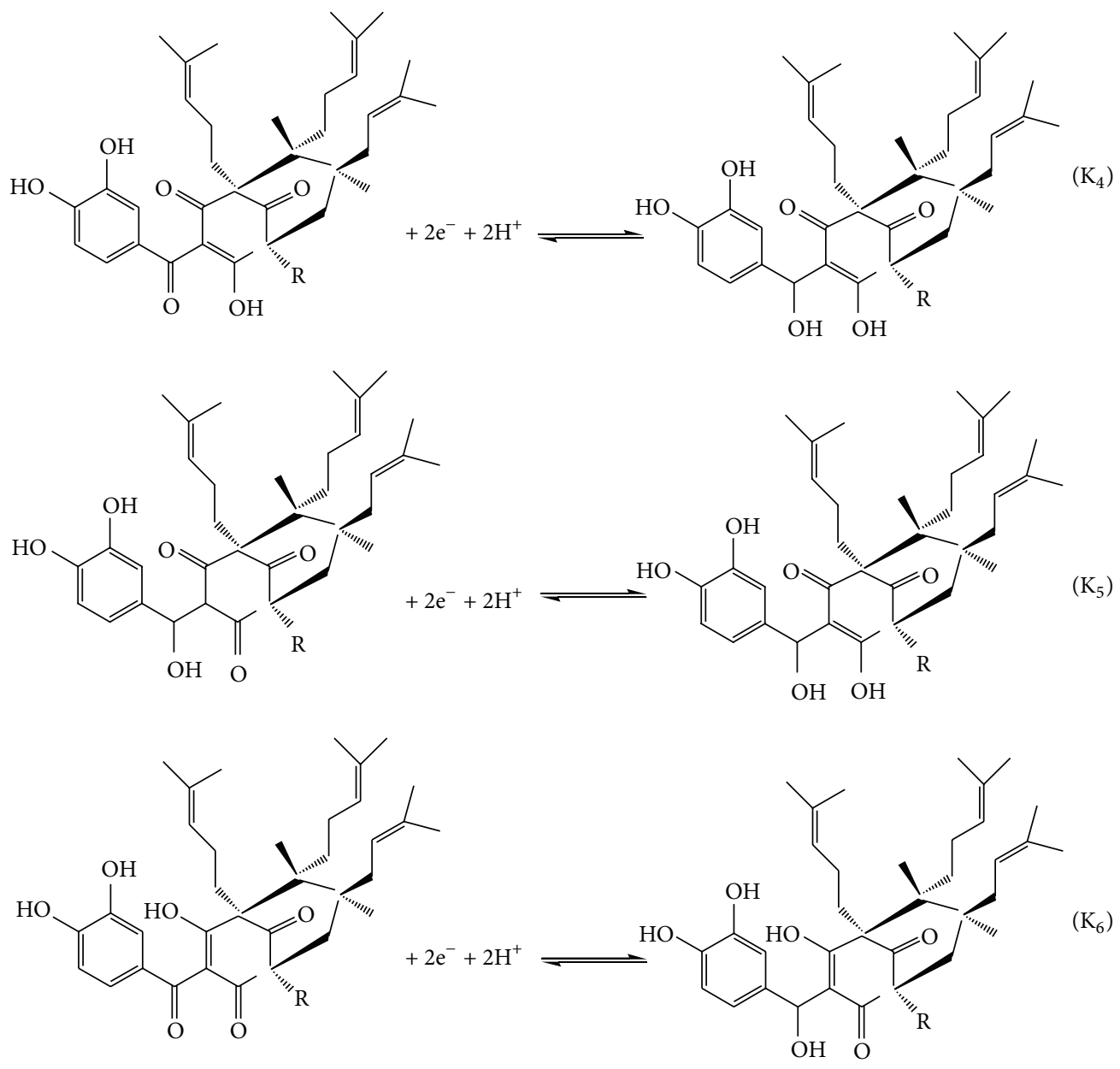

SCHEMe 3

This overall reaction comprises the $2 \mathrm{e}^{-} / 2 \mathrm{H}^{+}$redox transformation in the membrane along with the transfer of protons into the membrane.

\section{Conclusion}

The electrochemical study of a Gutifferone A (BP), revealed on the voltammogram the presence of three successive processes attributed to tautomerism reactions. Detailed voltammetric analysis of these signals reveals the structure of the chemical compound bearing the hydroxyl-moiety in the reduction mechanism. These differences are determined by the stability of intermolecular hydrogen-bonding. The results presented here are the first example of the use of the highly sensitive square wave voltammetry technique for the electrochemical study of Gutifferone A, and it is shown that this method can be used for the analytical determination of this class of natural compounds. We found that carbonyl group in $\mathrm{BP}$ can be reduced to a hydroxyl form through $2 \mathrm{e}^{-} / 2 \mathrm{H}^{+}$redox pathway coupled with the transfer of protons. BP undergoes three distinct reduction processes with each yielding a different form of $\mathrm{BPH}_{2}$. The three redox processes are assigned to three tautomer forms of BP formed by migration of a proton between the hydroxyl group in the position 3 and the adjacent carbonyl group in positions 1 and 10 .

\section{Acknowledgments}

This work was done with the support of AIRES-Sud, a programme of the French Ministry of Foreign and European Affairs implemented by the Institut de Recherche pour le Développement (IRD-DSF). The authors also acknowledge the support of the Academy of Science for the Developing World (Grant no. 07-052-LDC/CHE/AF/AC allowed to E. NgamenI's TWAS Research Unit). We thank Bruno Lenta (Département de Chimie, Ecole Normale Supérieure de Yaoundé (Cameroon)) for the kind gift of Gutifferone A.

\section{References}

[1] J. Lokvam, J. F. Braddock, P. B. Reichardt, and T. P. Clausen, "Two polyisoprenylated benzophenones from the trunk latex of Clusia grandiflora (Clusiaceae)," Phytochemistry, vol. 55, no. 1, pp. 29-34, 2000.

[2] B. Batanero, C. M. Sánchez-Sánchez, V. Montiel, A. Aldaz, and F. Barba, "Electrochemical synthesis of 3-phenylcinnamonitrile by reduction of benzophenone in acetonitrile," Electrochemistry Communications, vol. 5, no. 4, pp. 349-353, 2003. 
[3] P. J. Elving and J. T. Leone, "Mechanism of the electrochemical reduction of phenyl ketones," Journal of the American Chemical Society, vol. 80, no. 5, pp. 1021-1029, 1958.

[4] M. Suzuki and P. J. Elving, "Kinetics and mechanism for the electrochemical reduction of benzophenone in acidic media," Journal of Physical Chemistry, vol. 65, no. 3, pp. 391-398, 1961.

[5] W. Hamed, S. Brajeul, F. Mahuteau-Betzer et al., "Oblongifolins A-D, polyprenylated benzoylphloroglucinol derivatives from Garcinia oblongifolia," Journal of Natural Products, vol. 69, no. 5, pp. 774-777, 2006.

[6] K. R. Gustafson, J. W. Blunt, M. H. G. Munro et al., “The guttiferones, HIV-inhibitory benzophenones from Symphonia globulifera, Garcinia livingstonei, Garcinia ovalifolia and Clusia rosea," Tetrahedron, vol. 48, no. 46, pp. 10093-10102, 1992.

[7] N. G. Tsierkezos, "Investigation of the electrochemical reduction of benzophenone in aprotic solvents using the method of cyclic voltammetry," Journal of Solution Chemistry, vol. 36, no. 10, pp. 1301-1310, 2007.

[8] J. J. Magadula, M. C. Kapingu, M. Bezabih, and B. M. Abegaz, "Polyisoprenylated benzophenones from Garcinia semseii (Clusiaceae)," Phytochemistry Letters, vol. 1, no. 4, pp. 215-218, 2008.

[9] S. Sang, C.-H. Liao, M.-H. Pan et al., "Chemical studies on antioxidant mechanism of garcinol: analysis of radical reaction products of garcinol with peroxyl radicals and their antitumor activities," Tetrahedron, vol. 58, no. 51, pp. 10095-10102, 2002.

[10] K. Matsumoto, Y. Akao, E. Kobayashi et al., "Cytotoxic benzophenone derivatives from Garcinia species display a strong apoptosis-inducing effect against human leukemia cell lines," Biological \& Pharmaceutical Bulletin, vol. 26, no. 4, pp. 569-571, 2003.

[11] S. Baggett, P. Protiva, E. P. Mazzola et al., "Bioactive benzophenones from Garcinia xanthochymus fruits," Journal of Natural Products, vol. 68, no. 3, pp. 354-360, 2005.

[12] C. Ito, Y. Miyamoto, M. Nakayama, Y. Kawai, K. S. Rao, and H. Furukawa, "A novel depsidone and some new xanthones from Garcinia species," Chemical and Pharmaceutical Bulletin, vol. 45, no. 9, pp. 1403-1413, 1997.

[13] H. R. W. Dharmaratne, G. T. Tan, G. P. K. Marasinghe, and J. M. Pezzuto, "Inhibition of HIV-1 reverse transcriptase and HIV-1 replication by Calophyllum coumarins and xanthones," Planta Medica, vol. 68, no. 1, pp. 86-87, 2002.

[14] A. A. Isse, A. Galia, C. Belfiore, G. Silvestri, and A. Gennaro, "Electrochemical reduction and carboxylation of halobenzophenones," Journal of Electroanalytical Chemistry, vol. 526, no. 1-2, pp. 41-52, 2002.

[15] C. T. Ebelle, A. Nassi, E. Njanja, and E. Ngameni, "Characterization of lapachol in artificial organic-film membrane: application for the trans-membrane transport of $\mathrm{Mg}^{2+}$," Journal of Electroanalytical Chemistry, vol. 642, no. 1, pp. 61-68, 2010.

[16] D. C. M. Ferreira, M. O. F. Goulart, I. Tapsoba, S. Arbault, and C. Amatore, "Electrochemicalstudy of pharmacological activity at single cells: beta-lapachone effect on oxidative stress of macrophages," ECS Transactions, vol. 3, pp. 3-11, 2007.

[17] C. Frontana and I. González, "Structural factors affecting the reactivity of natural a-hydroxyquinones: an electrochemical and ESR study," ECS Transactions, vol. 3, pp. 13-23, 2007.

[18] C. Shi and F. C. Anson, "Simple electrochemical procedure for measuring the rates of electron transfer across liquid/liquid interfaces formed by coating graphite electrodes with thin layers of nitrobenzene," Journal of Physical Chemistry B, vol. 102, no. 49, pp. 9850-9854, 1998.
[19] C. Shi and F. C. Anson, "Electron transfer between reactants located on opposite sides of liquid/liquid interfaces," Journal of Physical Chemistry B, vol. 103, no. 30, pp. 6283-6289, 1999.

[20] A. M. O. Brett and M.-E. Ghica, "Electrochemical oxidation of quercetin,” Electroanalysis, vol. 15, no. 22, pp. 1745-1750, 2003.

[21] S. Ngouela, B. N. Lenta, D. T. Noungoue et al., "Anti-plasmodial and antioxidant activities of constituents of the seed shells of Symphonia globulifera Linn f," Phytochemistry, vol. 67, no. 3, pp. 302-306, 2006.

[22] S.-F. Zhao, J.-X. Lu, A. M. Bond, and J. Zhang, "Voltammetric studies in "wet" 1-butyl-1-methylpyrrolidinium bis(trifluoromethylsulfonyl)imide ionic liquid using electrodes with adhered microparticles," Electrochemistry Communications, vol. 16, no. 1, pp. 14-18, 2012.

[23] S.-F. Zhao, J.-X. Lu, A. M. Bond, and J. Zhang, "Remarkable sensitivity of the electrochemical reduction of benzophenone to proton availability in ionic liquids," Chemistry, vol. 18, no. 17, pp. 5290-5301, 2012.

[24] H. Li, F. Gao, C. Wang, J. Wang, and S. Zhang, "Molecular geometry optimization, two-photon absorption and electrochemistry of new diphenylethylene derivatives linking with benzophenone moiety through ether covalent bond," Journal of Fluorescence, vol. 21, no. 1, pp. 327-338, 2011.

[25] H. H. Girault and D. J. Schiffrin, "Electrochemistry of liquidliquid interfaces," in Electroanalytical Chemistry, A. J. Bard, Ed., vol. 15 of A series of Advances, pp. 1-132, Marcel Dekker, New York, NY, USA, 1989.

[26] V. Mirčeski, R. Gulaboski, I. Bogeski, and M. Hoth, "Redox chemistry of Ca-transporter 2-palmitoylhydroquinone in an artificial thin organic film membrane," Journal of Physical Chemistry C, vol. 111, no. 16, pp. 6068-6076, 2007.

[27] F. Marken, A. Neudeck, and A. M. Bond, "Cyclic voltammetry," in Electroanalytical Methods, F. Scholz, Ed., pp. 50-97, Springer, Berlin, Germany, 2002.

[28] V. Mirčeski, "Charge transfer kinetics in thin-film voltammetry. Theoretical study under conditions of square-wave voltammetry," Journal of Physical Chemistry B, vol. 108, no. 36, pp. 1371913725, 2004.

[29] A. Nassi, C. T. Ebelle, E. Njanja, and E. Ngameni, "Thinfilm voltammetry of a lutetium bisphthalocyanine at ionic liquid/water interface," Electroanalysis, vol. 23, no. 2, pp. 424-432, 2011.

[30] A. Sivakumar, S. J. Reddy, and V. R. Krishnan, "Voltammetric study of p-methylbenzophenone in aqueous media," Journal of the Electrochemical Society of India, vol. 33, no. 2, pp. 121-123, 1984.

[31] M. Lovric, "Square wave voltammetry," in Electroanalytical Methods, F. Scholz, Ed., Springer, Berlin, Germany, 2001.

[32] V. Mirceski, S. Komorsky-Lovric, Lovric, and M. Scholz F, Square-Wave Voltammetry, Theory and Application, Springer, Berlin, Germany, 2008.

[33] F. T. Martins, J. W. Cruz Jr., P. B. M. C. Derogis et al., "Natural polyprenylated benzophenones: keto-enol tautomerism and stereochemistry," Journal of the Brazilian Chemical Society, vol. 18, no. 8, pp. 1515-1523, 2007.

[34] A. Ashnagar, J. M. Bruce, P. L. Dutton, and R. C. Prince, "Oneand two-electron reduction of hydroxy-1,4-naphthoquinones and hydroxy-9,10-anthraquinones. The role of internal hydrogen bonding and its bearing on the redox chemistry of the anthracycline antitumour quinones," Biochimica et Biophysica Acta, vol. 801, no. 3, pp. 351-359, 1984. 

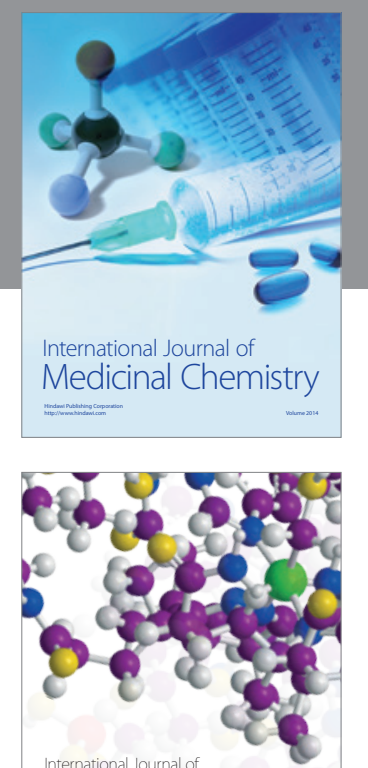

\section{Carbohydrate} Chemistry

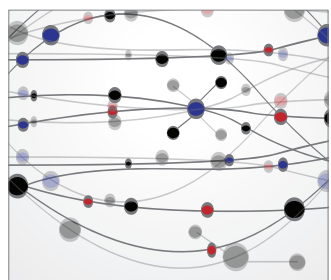

The Scientific World Journal
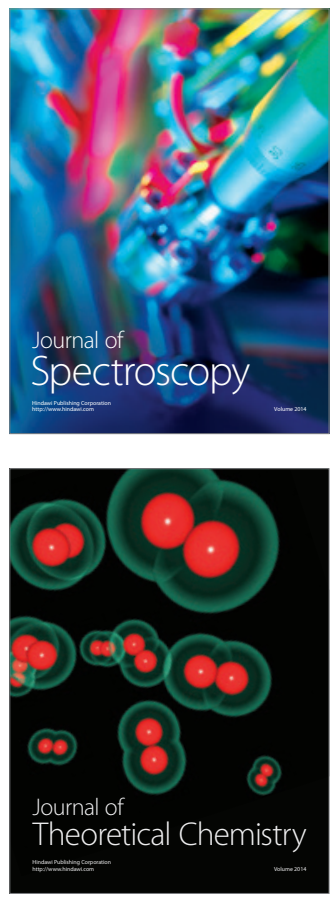
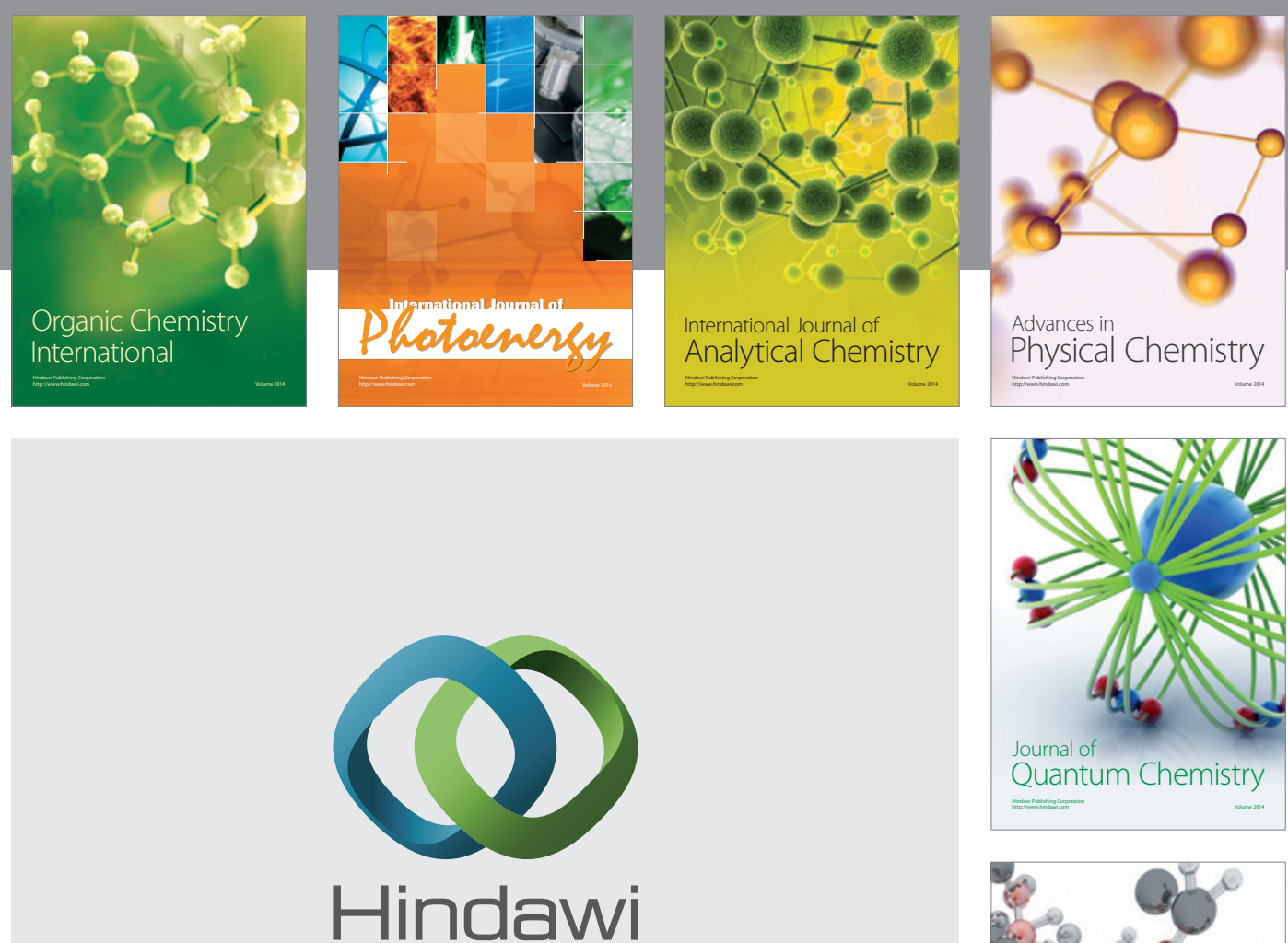

Submit your manuscripts at

http://www.hindawi.com

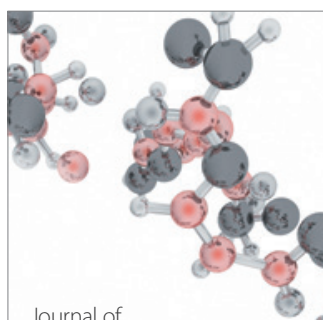

Analytical Methods

in Chemistry

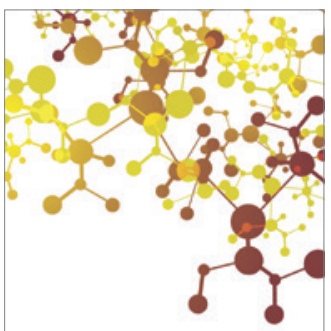

Journal of

Applied Chemistry

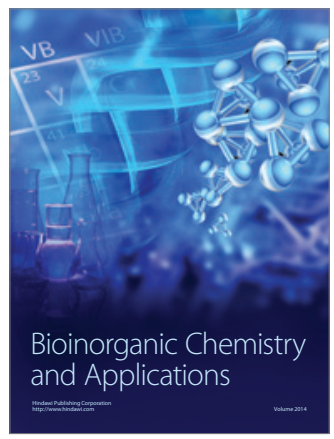

Inorganic Chemistry
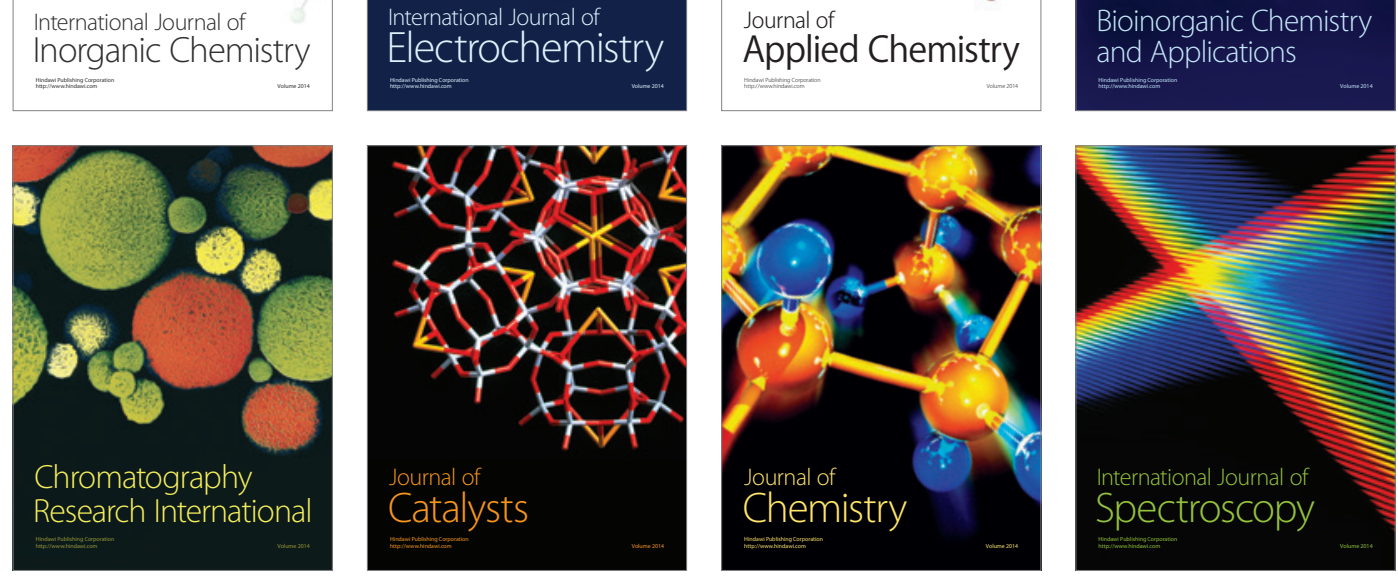